\title{
Using Small-scale Blast Tests and Numerical Modelling to Trace the Origin of Fines Generated in Blasting
}

\author{
Ivan Kukolj, Armin Iravani, and Finn Ouchterlony \\ Chair of Mining Engineering and Mineral Economics, Montanuniversitaet Leoben, Leoben, Austria
}

Received August 30, 2018; accepted September 5, 2018; published online September 25, 2018

\begin{abstract}
Waste fines from rock breakage often negatively influence economics and environment. The Austrian Science Fund (FWF) sponsors a project to investigate the cause of the fines by studying blast fragmentation throughout small-scale blast tests and numerical simulations. The tests include blast-loading confined granite and mortar cylinders by detonating cord with 6,12 , and $20 \mathrm{~g} / \mathrm{m}$ of PETN. The blast-driven dynamic cracking at the end face of the cylinder opposite to the initiation point is filmed with a high-speed camera. The filming is followed up by an analysis of surface and internal crack systems and sieving of the blasted cylinders to quantify the amount of fine material created. The numerical simulations cover the blast fragmentation of a mortar cylinder. These simulations use Finite and Discrete Element Methods (FEM, DEM) with explicit time integration. The model cylinders are loaded by a pressure evolution acting on the borehole wall. Both methods produce realistic crack patterns, consisting of through-going radial cracks with crack intersections around a crushed zone at the borehole. Furthermore, the DEM models have also yielded realistic fragment size distributions (FSD). The paper covers the present progress of the ongoing project and related future work.
\end{abstract}

Keywords: Blast-induced fines, Blast tests, High-speed photography, FEM, DEM, Dynamic cracking, Blast fragmentation

Untersuchungen zur Entstehung von sprenginduzierten Feinanteilen anhand von kleinmaßstäblichen Sprengversuchen und numerischer Modellierung

Zusammenfassung: Bei Gesteinssprengungen entstehende, nicht verwertbare Feinanteile haben oft einen negativen Einfluss auf Umwelt und Wirtschaftlichkeit. Der Österrei-

\footnotetext{
I. Kukolj, MSc ( $\square)$

Chair of Mining Engineering and Mineral Economics,

Montanuniversitaet Leoben,

Erzherzog-Johann-Str. 3,

8700 Leoben, Austria

ivan.kukolj@unileoben.ac.at
}

chische Wissenschaftsfonds (FWF) fördert ein Projekt zur Untersuchung der Ursache von Feinanteilen durch Analyse der Zerkleinerung in kleinmaßstäblichen Sprengversuchen und numerische Modellierung. Die Tests umfassen Sprengversuche an Granit- und Mörtelzylindern mit 6, 12 und $20 \mathrm{~g} / \mathrm{m}$ PETN Sprengschnur. Die dynamische Rissbildung an der dem Initiationspunkt gegenüberliegenden Stirnseite des Zylinders wird mit einer Hochgeschwindigkeitskamera aufgenommen. Im Anschluss an die Aufnahme erfolgt eine Analyse der oberflächlichen und inneren Risssysteme sowie eine Siebanalyse des gesprengten Materials, um die Masse des entstehenden Feinmaterials zu quantifizieren. Die numerischen Simulationen modellieren die Zerkleinerung eines Mörtelzylinders. Es werden Finite- und Diskrete-Elemente-Methoden (FEM, DEM) mit expliziter Zeitintegration verwendet. Die Modellzylinder werden durch eine, auf die Bohrlochwand wirkende, Druckentwicklung belastet. Beide Methoden produzieren realistische Rissmuster, bestehend aus durchgehenden radialen Rissen mit Rissübergängen (Vereinigung und Unterteilung) rund um eine Zermalmungszone am Bohrloch. Darüber hinaus haben die DEM-Modelle auch eine realistische Korngrößenverteilung geliefert. Der Beitrag behandelt den aktuellen Fortschritt des laufenden Projekts sowie damit verbundene zukünftige Arbeiten.

Schlüsselwörter: Sprenginduzierte Feinanteile, Sprengversuche, Hochgeschwindigkeitsfotografie, FEM, DEM, Dynamische Rissbildung, Sprengzerkleinerung

\section{Introduction}

The amounts of mineral fines that are associated with raw materials extraction have practical consequences. One concern is the sustainability of natural resources since fines are often an unsellable liability or waste that has cost money and energy to produce and in the end has to be deposited. This reasoning lay behind the EU project Less Fines [1]. The health aspects of mineral fines have again come into focus, so sources of respirable dust and miti- 
Fig. 1: Volume of crushed material around an extended 2D blast-hole (Fig. 2 in [7]); the crushed zone volume $V_{c}$ is an nular and the breakage zone volume $\mathrm{V}_{\mathrm{b}}$, which also generates crushed fines, is made up of the $n$ partial volumes of the star arms
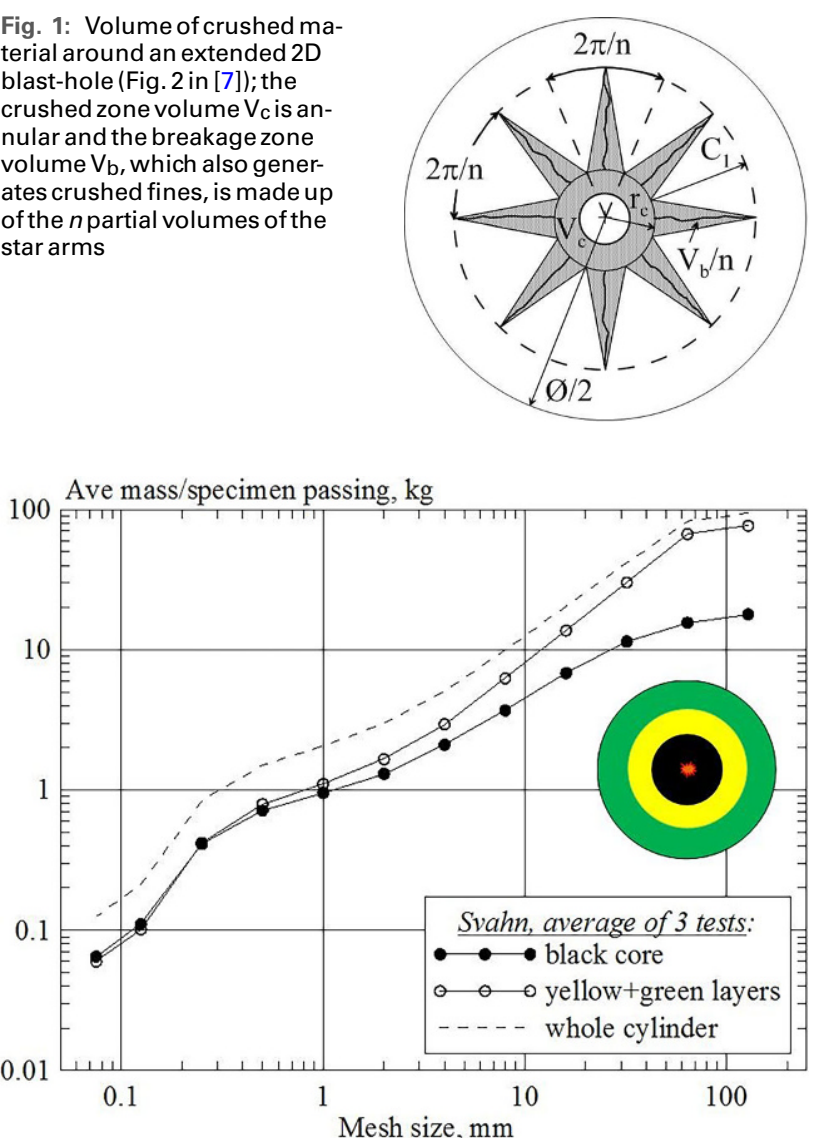

Fig. 2: Sieving curves for blasted multilayered $\emptyset 300 \times 600$-mm cylinders ofmortar; comparison of Ø120-mm black corewith yellow (Ø120-200 mm + green layers $(\varnothing 200-300 \mathrm{~mm})[8]$

gation effects are studied in the ongoing EU Horizon 2020 project "Sustainable Low Impact Mining, SLIM" [2, 3].

Blasting is a major producer of waste fines, crushing and milling another. Blasting is a highly dynamic process and the crack growth that defines breakage is a major source of fines. Such crack-generated fines (CGF) are also produced by crushing and grinding. Fines are inherently related to the amount of energy required in comminution. Most of the area created resides in the fines and this area then determines the consumed comminution energy [4]. A better knowledge of how CGF are generated may also help to improve blasting and crushing practices and to suppress the amount of CGF at the source rather than dealing with them afterwards.

Blast generated fines are often considered to originate mainly from the annular crushed zone around a blast hole, which contains only $-1 \mathrm{~mm}$ material, and fragmentation models were built around this; e.g. the CZM or crush zone model $[5,6]$. It implies that fragment size is (almost) solely defined by the distance to the blast hole, the finest material created at the borehole wall and fragment size, thus, increasing with distance from the blast hole. The circu-
Fig. 3: Post-blast cross section through blasted confined mortar cylinder [9]

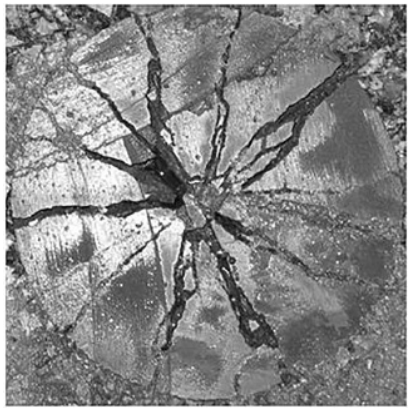

MM10_5 10g 44mm

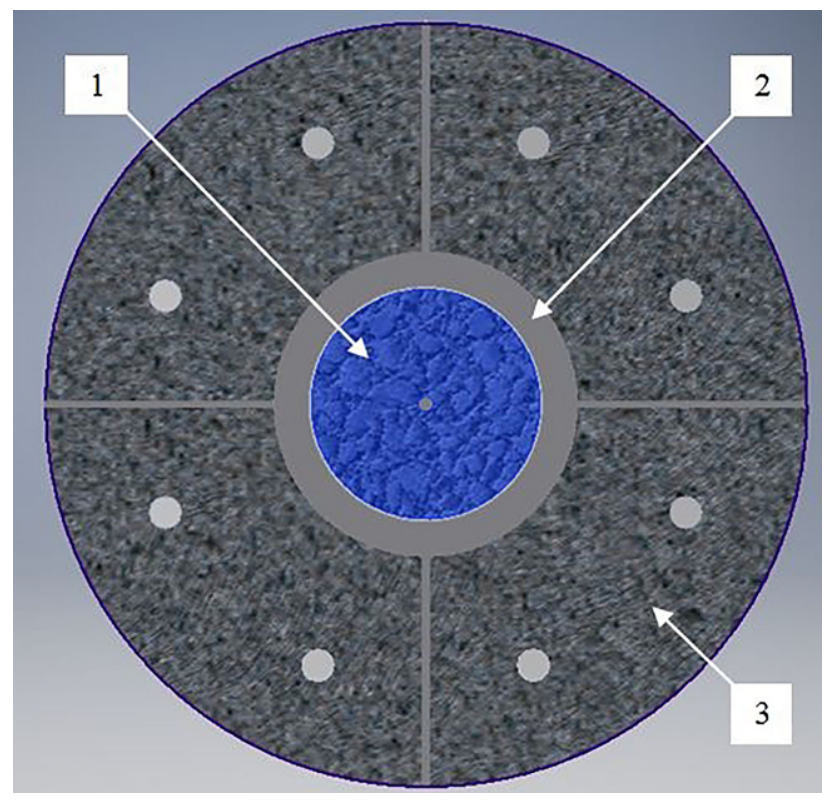

Fig. 4: Prepared blast chamber (transverse cross-section) (1-Blast cylinder; 2-Damping layer; 3-Blast chamber)

lar crushed-zone model was extended to a star-shape one (Fig. 1; [7]).

Blasting tests with layered cylinder specimens [8] contradict the predictions of the star-shaped CZM (Fig. 2). Firstly, the sieving curves for the layers are quite similar in shape and the core region contains fragments well beyond $1 \mathrm{~mm}$ in size. Secondly, there is a cross-over point $(0.25 \mathrm{~mm}$ in Fig. 2) above which the outer layers contain more fine material than the core. Consequently, more $-1 \mathrm{~mm}$ fines are created outside the black core than inside it.

Post-mortem crack patterns are not as simple either as the CZM (Fig. 3; [9]). Here the cracks have seemingly run along crooked paths, branched, merged, and left debris along the crack paths.

Statistical models of brittle fragmentation [10,11] point in the same direction, that instability of fast propagating cracks leaves behind a trace of small fragments along their propagation paths, but this has not been observed in rock under blasting-like conditions. More arguments are provided in [12].

This led to the FWF-sponsored project P27594-N29: "Fines generated by dynamic crack propagation, as in blasting of rock-like materials," which ends Dec 31, 2018. 


\begin{tabular}{|c|c|c|c|c|c|c|}
\hline \multirow[t]{2}{*}{ Property } & \multicolumn{2}{|l|}{ Granite } & \multicolumn{2}{|l|}{ Mortar } & \multicolumn{2}{|c|}{ Damping } \\
\hline & Mean & St.dev & Mean & St.dev & Mean & St.dev \\
\hline UCS [MPa] & 171.50 & 9.00 & 27.70 & 1.10 & - & - \\
\hline Brazilian tensile strength [MPa] & 10.85 & 1.52 & 2.90 & 0.49 & - & - \\
\hline Density $\left[\mathrm{g} / \mathrm{cm}^{3}\right]$ & 2.70 & 0.01 & 1.66 & 0.01 & 2.12 & 0.08 \\
\hline Young's modulus [GPa] & 65.30 & 0.83 & 12.20 & 0.31 & - & - \\
\hline Poisson's ratio [-] & 0.24 & 0.02 & 0.23 & 0.05 & - & - \\
\hline$P$-wave velocity $[\mathrm{m} / \mathrm{s}]$ & 4908 & 111 & 3069 & 62 & 1210 & 274 \\
\hline$S$-wave velocity $[\mathrm{m} / \mathrm{s}]$ & 3212 & 150 & 2065 & 40 & 643 & 79 \\
\hline
\end{tabular}

Two main project objectives are to: i) determine the importance of the dynamic mechanism for CGF by capturing images of branching at a moving crack tip and ii) compare the measured fragment size distribution (FSD) with models based either on the mechanism of crack branching and merging or other mechanisms. The first part of this project is described in $[13,14]$, progress in numerical simulations in [15], and the present state in this paper. It is divided into an experimental part and a part with numerical simulations.

\section{Methodology}

\subsection{Small-scale Blast Tests}

The blast tests [13] include controlled blast loading of a confined hollow cylinder whilst the resulting dynamic cracking is filmed at its frontal end face by means of high-speed photography.

The cylinder is made of mortar or granite, $\varnothing 150 \times 300 \mathrm{~mm}$ in size, with a $\varnothing 10-\mathrm{mm}$ central axial borehole. The production of the blast cylinders is described in [13].

The loading is achieved by detonating a decoupled PETN (Pentaerythritol tetranitrate) cord $(6,12$, or $20 \mathrm{~g} / \mathrm{m}$ ) inside the borehole. The detonation propagates along the cord towards a stemming plug at the frontal end face with the velocity (VOD) of about $7300 \mathrm{~m} / \mathrm{s}$ [16].

The cylinder is radially confined by a 25-mm-thick damping layer inside a blast chamber (Fig. 4). The damping material [13] is a commercial concrete mixture, cured for one day. It improves the acoustic-impedance matching of propagating shock waves and protects the chamber.

Table 1 shows measured material properties of the blast cylinders and the damping layer.

The blast chamber (Fig. 5) includes four concrete segments, axially connected with two metal plates. The segments are designed to radially move about $5 \mathrm{~mm}$ during the blast, acting as 'impulse traps' [17]. The rear metal plate includes an opening for inserting the cord. The frontal metal plate includes an opening, allowing filming of the frontal end face through a protective polycarbonate window.

The filming [13] captures crack development at the end face following the detonation. The cracking at the end face starts about when the detonation front reaches the stemming plug, which is seen as slight movement of the plug and occasionally a dimmed detonation-flash around it.
The filming set-up (Fig. 6) records the dynamic crack development, in most cases, with $24,656 \mathrm{fps}$ at $336 \times 336$ pixels.

\subsection{Numerical Modelling}

\subsubsection{Modelling in Abaqus}

Numerical modelling of blast fragmentation was done using the finite element method (FEM) and the discrete element method (DEM) [14]. The FEM approach (Abaqus) is suitable for modelling blast-induced damage, though presently quite limited for fragmentation analysis [14].

\subsubsection{HiDEM Model}

Blast cylinders are modelled with a 3D discrete element code (HiDEM) [11, 18]. A dynamic sedimentation method is used to generate the initial random structure of the model composed of rigid spheres of 2-mm and 3-mm diameter. Contacts between the particles are modelled using massless beams. The interaction potential between two particles is defined by the Euler-Bernoulli (EB) beam model. Estimates of the beam elastic energy are provided in [18]. The beams break due to excerted tension, shear, or bending beyond the fracture limit (Fig. 4 in [18]).

The particle-motion equation is given in [14]. The model assumes elastic-material behaviour. The stiffness matrix for linear-elastic EB beams under small deformation is provided in [18]. The modelled material has an elastic modulus of $E=19.7 \mathrm{GPa}$ and a Poisson's ratio of $v=0.19$, which is somewhat representative of the blast-test mortar. The stochastic mechanical behaviour of granular disordered materials was modelled using beams with reduced stiffness. These beams were randomly selected to have their stiffness reduced to $10 \%$ of the original value. Here, the fracture criterion $[11,18]$ was described by the elasticstrain threshold $\varepsilon_{\text {crit }}=0.0003$.

The modelled mortar cylinders are $\varnothing 140 \times 280 \mathrm{~mm}$ in size with a $\emptyset 10-\mathrm{mm}$ borehole. The blast loading is radially applied onto the borehole wall according to a pressure-time function [14]. The modelled VOD is the same as in the blast tests. A simplified post-peak pressure drives all particles outwards with $P_{\text {post }}=0.0025 P_{\text {peak }}$. The modelling uses three peak pressures of $166 \mathrm{MPa}, 85 \mathrm{MPa}$, and $35 \mathrm{MPa}$, equiva- 


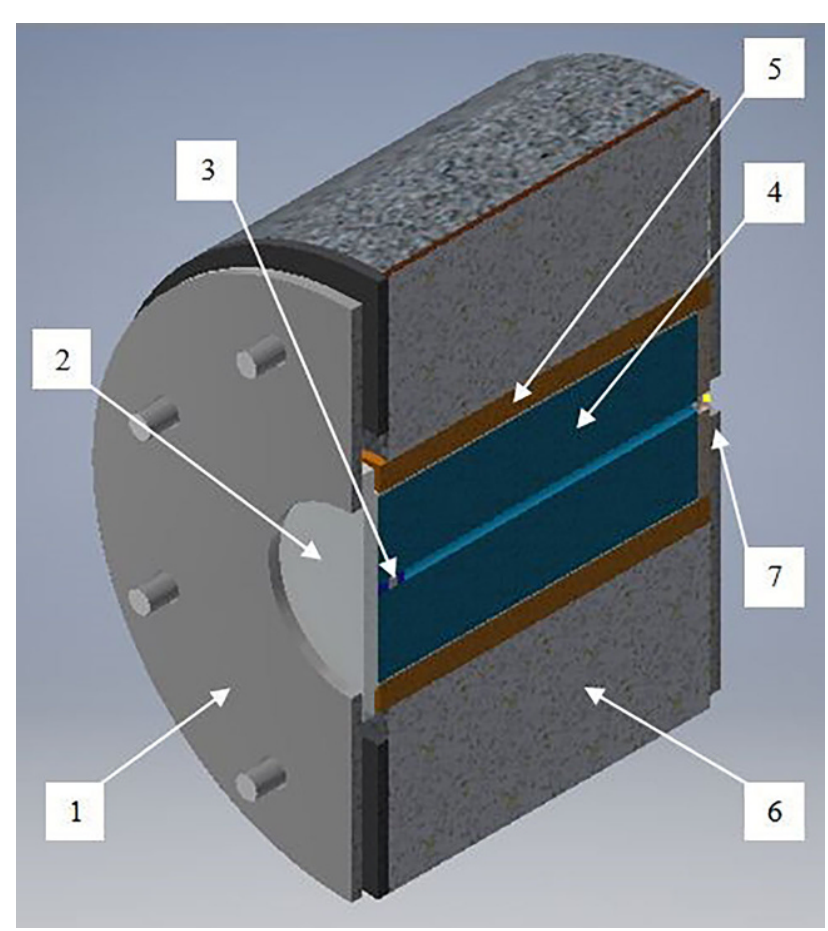

Fig. 5: Prepared blast chamber (axial cross-section) (1-Frontal end metal plate; 2-Protective window; 3-Boreholewith stemming; 4-Blast cylinder; 5-Damping layer; 6 -Chamber segment; 7 -Rear-end metal plate)

lent to $20 \mathrm{~g} / \mathrm{m}, 12 \mathrm{~g} / \mathrm{m}$, and $6 \mathrm{~g} / \mathrm{m}$ of PETN [14]. In addition, $20 \mathrm{~mm}$ of stemming was included. Quiet boundary conditions are applied to the mantle to avoid cracking due to reflected tensile waves.

\subsubsection{Simplified n(s) Model}

When blasted, the cylinder expands radially, inducing tangential tension and tensile cracks. In the crushing process, fragments are broken by continual shear deformation [19]. Such a process has a power-law FSD $n_{\text {crush }}(s) d s=C_{1} s^{-\beta} d s$ [11], where $C_{1}$ is a constant and $\beta$ indicates the degree of crushing/grinding, being $\beta \sim 1.8-3.5$ when dimension $D=3$ $[11,15]$. Dimensionless size $s$ is measured in number of grains composing a fragment [15].

The dynamic tensile cracks can easily become unstable, branch, and further merge, forming fragments. This inherently-universal process leads to a characteristic FSD [11, 20]. The number of fragments $n_{b m}(s)$ of size $s$ in an interval ds can be written as $\mathrm{n}_{\mathrm{bm}}(\mathrm{s}) \mathrm{ds}=\mathrm{C}_{2} \mathrm{~s}^{-\alpha} \exp \left(-\mathrm{s} / \mathrm{C}_{3}\right) \mathrm{ds}$ with $\alpha=(2 D-1) / D$, where $C_{2}$ and $C_{3}$ are non-universal constants $[11,15]$.

If $n(s)$ describes the number-density of fragments with s number of grains, the FSD, or the number of fragments in a size-interval ds, can then be written as [15]:

$$
\mathrm{n}(\mathrm{s}) \mathrm{ds}=\mathrm{C}_{1} \mathrm{~s}^{-\beta} \mathrm{ds}+\mathrm{C}_{2} \mathrm{~s}^{-\alpha} \exp \left(-\mathrm{s} / \mathrm{C}_{3}\right) \mathrm{ds}+\mathrm{n}_{\mathrm{b}}(\mathrm{s}) \mathrm{ds}
$$

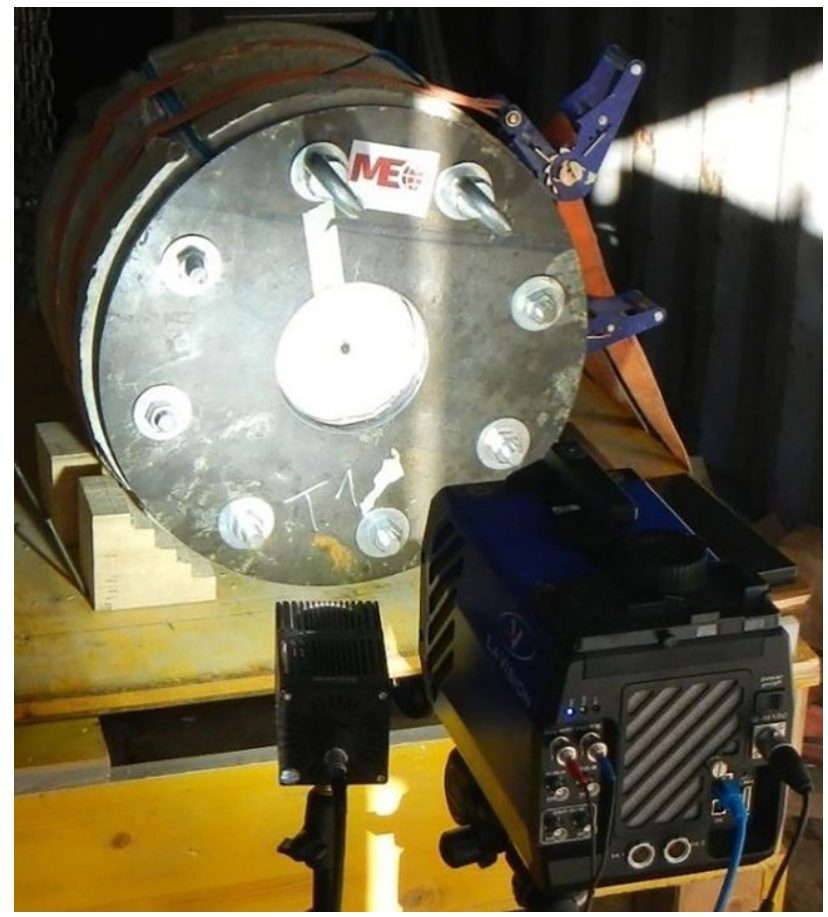

Fig. 6: High-speed filming set-up for the blast tests

where the boulder intensity $n_{b}$ is given by the characteristic boulder size $\mathrm{s}_{\mathrm{b}}$ and

$$
\mathrm{n}_{\mathrm{b}}(\mathrm{s})=\exp \left(-\mathrm{s} / \mathrm{s}_{\mathrm{b}}\right)
$$

With the proper transformation from s to r, i.e. $d s \propto r^{2} d r$ for $D=3$, leaving the exponential part of the second term in the $\mathrm{n}(\mathrm{s})$ formula and integrating the $\mathrm{n}(\mathrm{s})$, the mass passing fraction at screen size $r(M P F(r))$ can be approximated for fragments smaller than boulders [15]:

$$
\operatorname{MPF}(r)=f_{c r}\left[1.0-\left(r / r_{\text {grain }}\right)^{(-3 \beta+6)}\right]+f_{b m}\left(r / r_{\text {max }}\right)^{(-2 \alpha+6)}
$$

where $f_{b m}$ and $f_{c r}$ determine the mass fraction of fragments formed in the branching-merging and the crushing process, $r_{\text {grain }}$ is the approximated diameter of the material grain size, and $r_{\text {max }}$ is the approximated diameter of the largest fragment.

\section{Preliminary Results}

\subsection{Crack Patterns}

The high-speed images (Fig. 7) show more intensive cracking with the increase of charge. Similarly, crack patterns are denser and develop earlier in granite than in mortar. The high-speed images of both mortar and granite shots show three phases of crack development [13].

Firstly, following the plug movement, initial cracks emerge and propagate mainly in the radial direction. In 


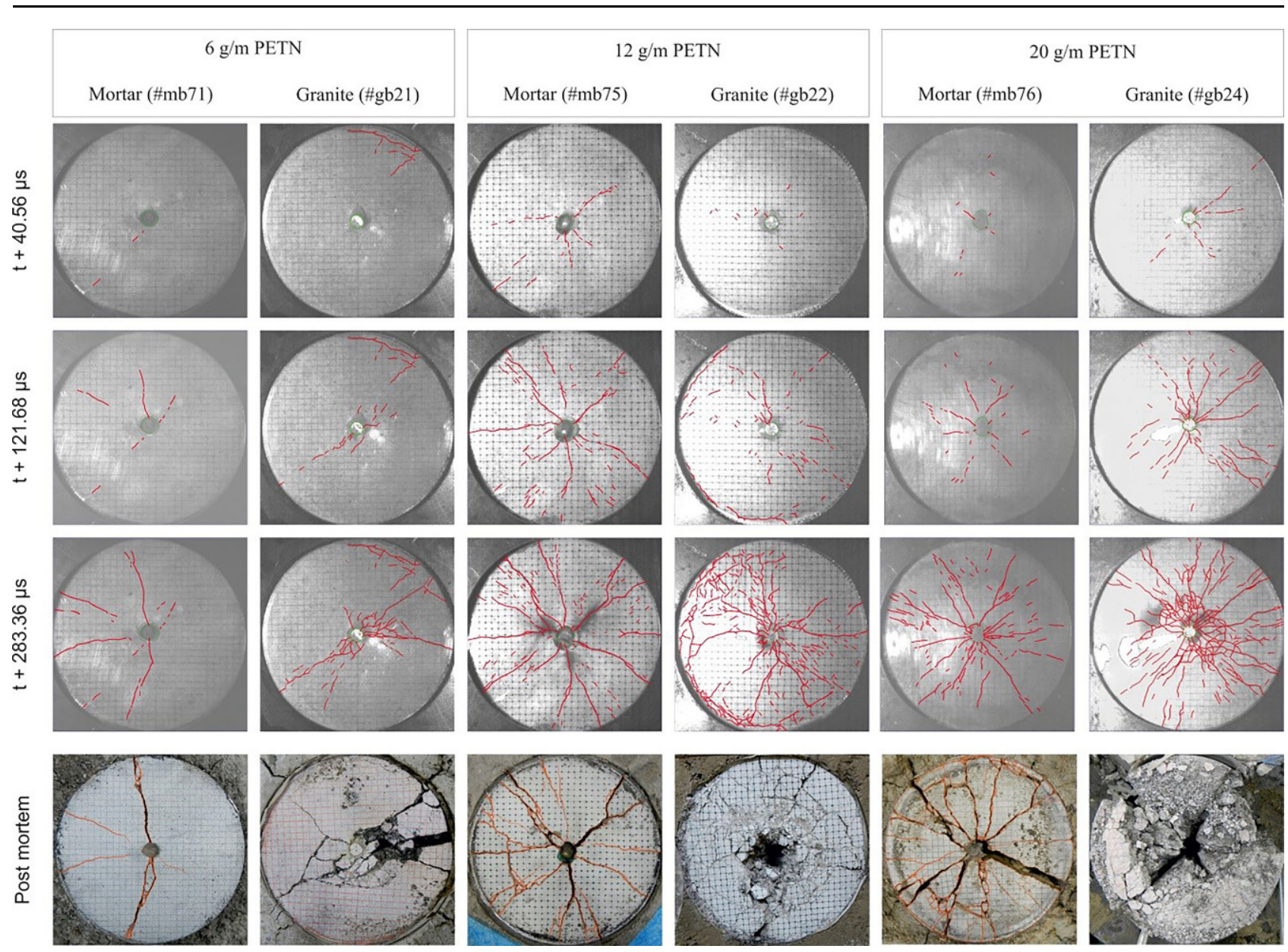

Fig. 7: High-speed and post-mortem end-face images of the cylinders with respect to the charge and material
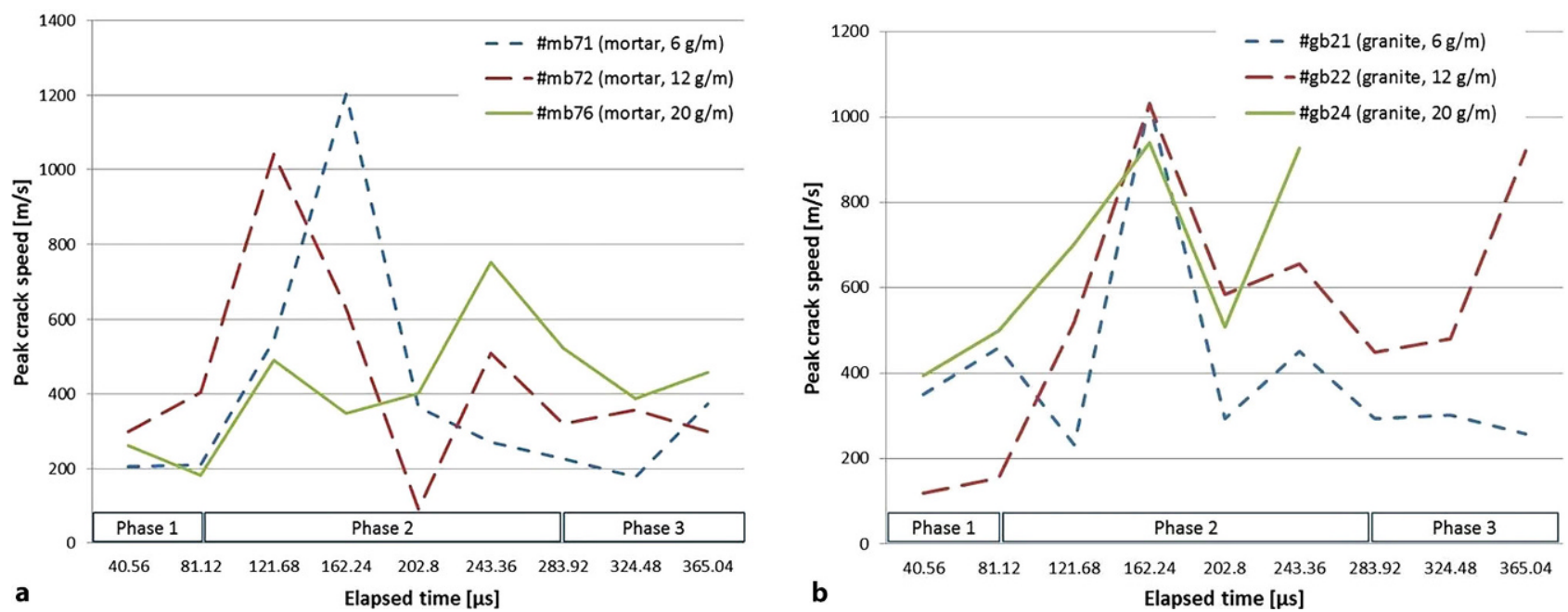

Fig. 8: Peak crack speed in blast cylinders with respect to material, charge amount, and elapsed time (a Mortar curve set; b Granite curve set) 

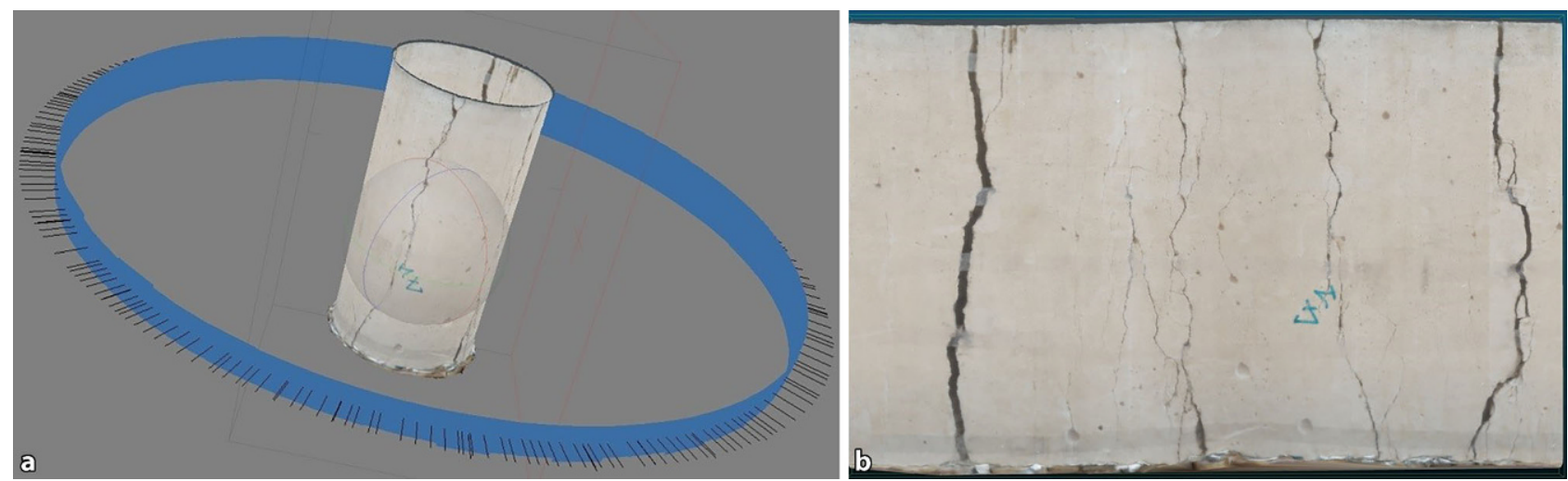

Fig. 9: Post-mortem mantle image (a Processing; $\mathbf{b}$ “Unfolded" mantle, cylinder \#mb71)

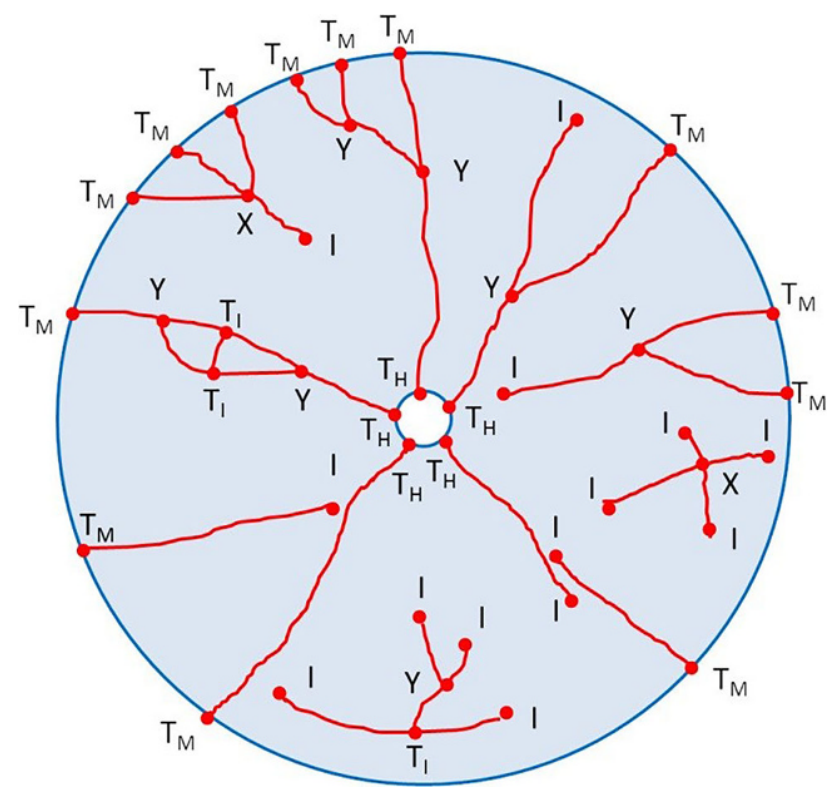

Fig. 10: Topological representation of crack-pattern features

the second phase, the crack-propagation speed reaches its peak and quickly drops with multiple cracks branchingmerging (Fig. 8). After the second phase, the main cracks have reached the borehole and/or the mantle and end-face spalling with fumes leakage may occur.

The post-mortem crack patterns are observed at the end face (Fig. 7), on the mantle, and internally through computer tomography (CT) [13].

The mantle crack patterns are firstly photographed and then processed in Agisoft PhotoScan ${ }^{\circledR}$ to produce a $3 D$ model of the mantle, which is then projected onto a $2 \mathrm{D}$ image for further analysis (Fig. 9).

So far the CT cross-sections and mantle images indicated that the number of main cracks and the number of main intersections basically do not change in the axial direction [13].

The crack patterns in the high-speed and post-mortem images are traced and topologically analysed, similarly as in [21]. This includes decomposition of a crack network into topological features (Fig. 10): branches, crack intersections
( $\mathrm{J}_{\text {int: }}: X, Y$, and $\left.T_{1}\right)$, borehole intersections $\left(T_{H}\right)$, mantle intersections ( $\left.T_{M}\right)$, and crack-end nodes (I).

The analysis quantifies the development of the features in the images with respect to time, from $40.56 \mu$ s to $527.28 \mu \mathrm{s}$ and finally to the post-mortem state $(\mathrm{pm})$. The results are presented in a ternary diagram with respect to the percentage of the feature categories (Fig. 11).

The results show that the percentage of crack intersections rapidly increases and the percentage of end nodes drops during the second phase, as the initial smaller cracks coalesce.

The number of active end nodes (i.e. propagating crack tips) and intersections both increase with the increase of charge and more so in granite than in mortar.

Fig. 12 shows resulting 3D crack networks from the modelling with respect to the three loading levels at $t=400 \mu \mathrm{s}$. By increasing the loading level, the internal damage intensity increases. Accordingly, the crack system becomes more complex, increasing in number of main radial cracks and intersections.

\subsection{Fragmentation Analysis of Blasted Cylinders}

Fig. 13 shows sieving FSD curves of selected blast cylinders. The curves shift upwards to contain larger fractions of fines when the charge is increased, in accordance with the Natural Breakage Characteristics (NBC) properties [4]. The curve-fitting procedure is ongoing.

\subsection{Numerical Estimates of Fragmentation and Fines Sources}

Fig. 14 shows FSD curves obtained with HiDEM modelling. A fragment is defined by the number of connected particles $N$ and the screen size is that of the diameter of a volume-equivalent sphere. The curves represent the masspassing fraction of the model for different blast-loading levels. The curve with $\mathrm{P}_{\text {peak }}=166 \mathrm{MPa}$ is similar to the sieving curves and well approximated by the Swebrec function [22]. The FSD curves from the DEM simulations also show an NBC-like relationship. 
Fig. 11: Results from the topological analysis (cylinder \#mb75); the data points relate to crack-pattern state with respect to elapsed time

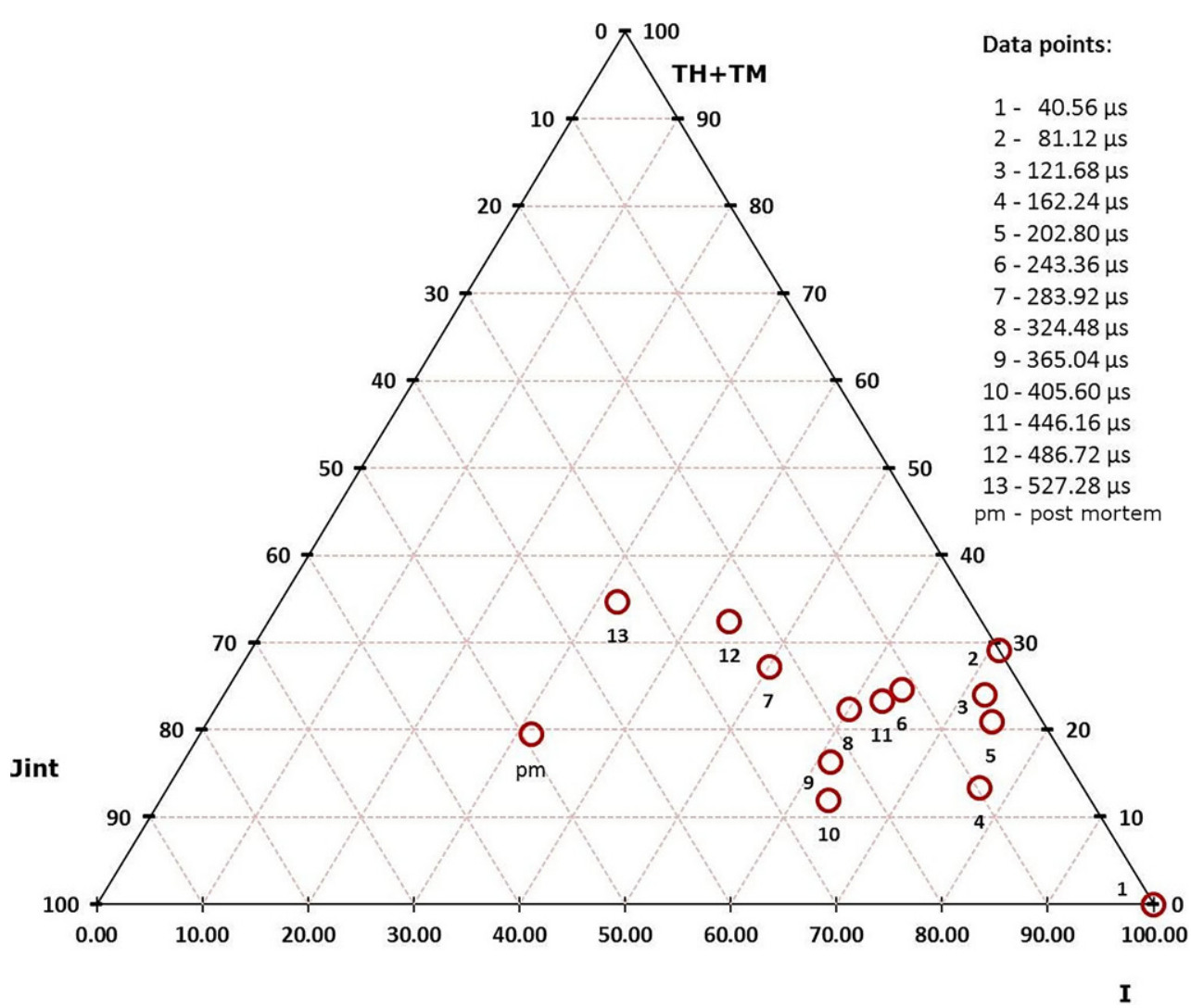

$35 \mathrm{MPa}$

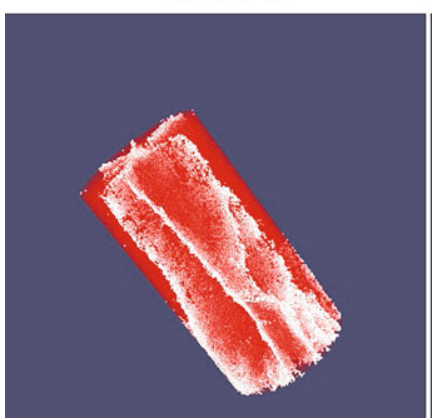

$85 \mathrm{MPa}$

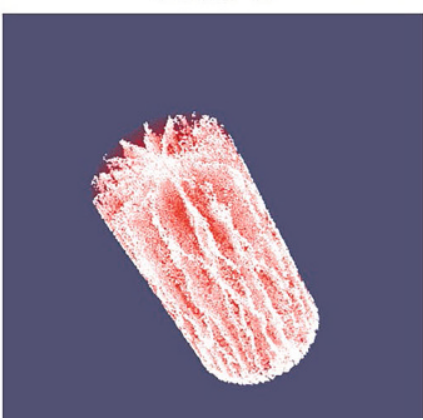

$166 \mathrm{MPa}$

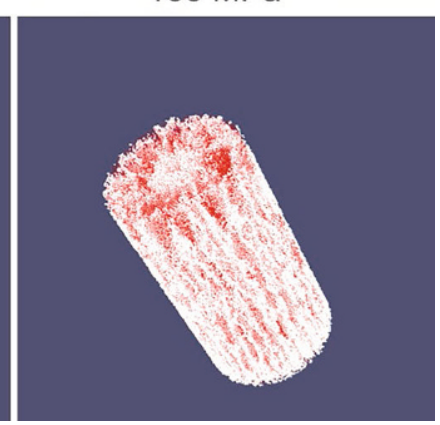

At $35 \mathrm{MPa}$ and $85 \mathrm{MPa}$, the mass-passing curves indicate the "dust and boulders" phenomenon. The curve with $P_{\text {peak }}=35 \mathrm{MPa}$ contains $94 \%$ of the cylinder mass in one boulder. The curve with $P_{\text {peak }}=85 \mathrm{MPa}$ contains a wider range of fragment sizes and four boulders, with almost $50 \%$ of the cylinder mass. This results from blasting below the critical charge level $[9,12]$.

By using Eq. 3, the percentage mass fraction of fragments formed by branching-merging and crushing [15] can be determined for the results (Table 2). The size of the branching-merging fragments ranges from a single DEM particle to a maximum value, which depends on the applied loading level. Similar to the MPF, the size of these fragments is approximated by the diameter of the volume equivalent sphere.

Simulations have also been conducted with radially-layered mortar cylinders, like those in [8]. The cylinders are banded at radii $r=30 \mathrm{~mm}$ and $r=50 \mathrm{~mm}$, creating three concentric regions. A routine calculates the absolute mass of very fine particles containing only one DEM particle in each region. Fig. 15 shows that the absolute mass of the fines in region $3(50 \mathrm{~mm}<\mathrm{r}<70 \mathrm{~mm})$ is larger than in region 1 $(5 \mathrm{~mm}<\mathrm{r}<30 \mathrm{~mm})$, thus confirming the results from [8].

\section{Conclusions}

The ongoing project studies dynamic mechanisms behind blast-induced fines.

The filming shows a three-phase crack-pattern development. The main cracks and intersections in mortar are more numerous and appear earlier with higher charge and the same tendencies are observed in granite, but at a higher level. They are detectable before the third phase and do 
Fig. 13: Selected sieving curves of blasted cylinders (a Mortar curve set; b Granite curve set)
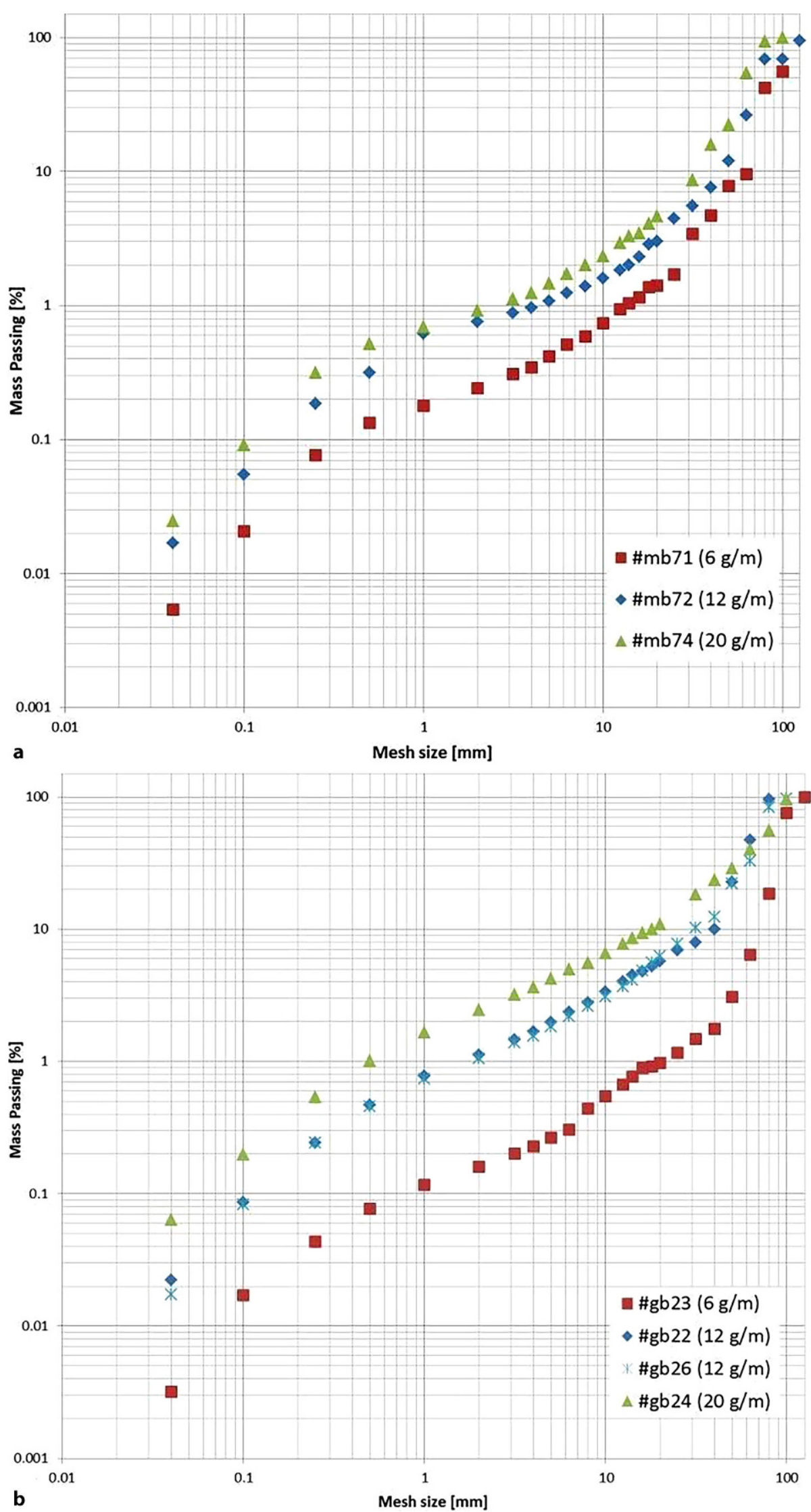


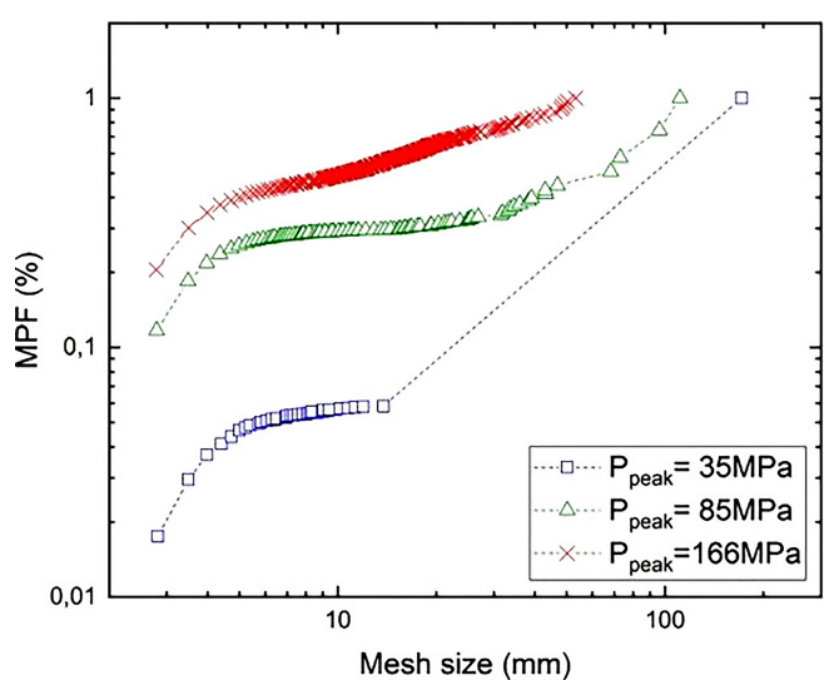

Fig. 14: FSD curves of modelled cylinders

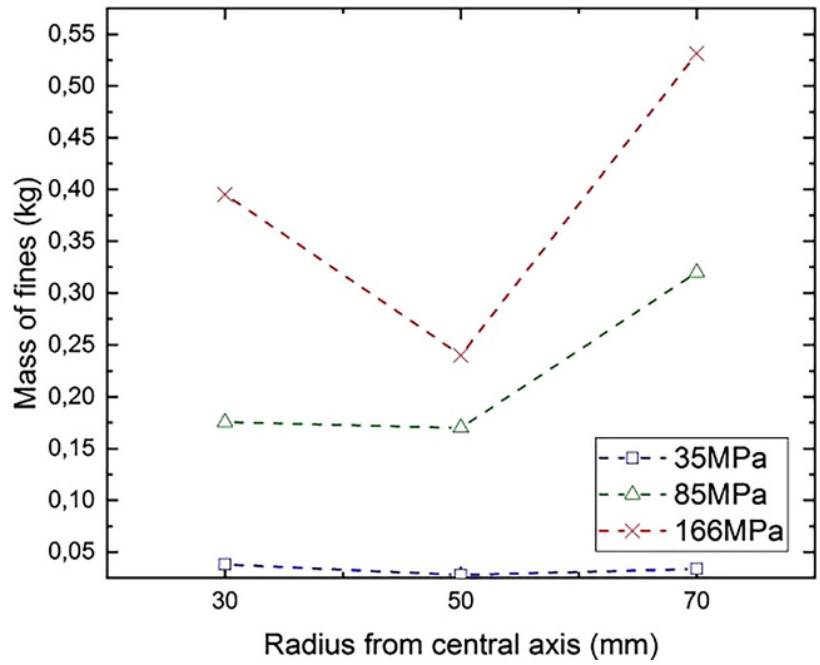

Fig. 15: Absolute mass of fine-particles with respect to the radius from the borehole

\begin{tabular}{|c|c|c|c|c|c|}
\hline \multirow[t]{2}{*}{$P_{\text {peak }}$} & \multicolumn{4}{|c|}{ Fragment mass percentage [\%] } & \multirow{2}{*}{$\begin{array}{l}\text { Max. diameter of branching-merging } \\
\text { fragments } \\
r_{\max }[\mathrm{mm}]\end{array}$} \\
\hline & Crushing & Branching-merging & Boulders & $\begin{array}{l}\text { Branching-merging } \\
\text { (<10 particles) }\end{array}$ & \\
\hline 35 & 4.5 & 1.5 & 94 & 0.5 & 14.1 \\
\hline 85 & 26.5 & 19.6 & 53.9 & 1.1 & 70.9 \\
\hline 166 & 37.5 & 55.3 & 7.1 & 4.3 & 52.4 \\
\hline
\end{tabular}

not significantly change in the axial direction. Although the crack speed is higher in mortar [13], crack patterns develop with more propagating crack tips in granite.

The numerical modelling has used the finite element method (Abaqus) and the discrete element method (HiDEM) with explicit time integration to model the dynamic crack propagation, branching and merging, and blast fragmentation of mortar cylinders. The FEM simulations provided results on dynamic $2 \mathrm{D}$ crack propagation, whereas the $3 \mathrm{D}$ behaviour has been more successfully simulated with the DEM code (HiDEM).

The HiDEM code provides realistic FSD results of blasted mortar cylinders, focusing on three major fragmentation mechanisms: borehole crushing, branching-merging, and secondary crushing of branching-merging fragments. The modelling results are in general agreement with the layered-cylinder blast results [8].

The FSD sieving curves of both blasted and modelled cylinders follow reasonably well the NBC parallel upward shift with the charge increase.

Future work will include further topological analysis of the images, analysis of blast-induced 3D crack patterns, determining other possible fines-generating mechanisms acting in the high-speed images, and further fragmentation analysis of the modelled and the blasted cylinders, including laser diffractometry for the grain sizes below $40 \mu \mathrm{m}$. The comparison of the simulation results with the blast-test results will take place after necessary calibrations. The final results will determine the relative influence of observed dynamic mechanisms on the fines generation and a discussion of how the fines could be suppressed.

Acknowledgements. The project is funded by Austrian Science Fund (FWF): P27594-N29. The authors would like to thank Dr. Jan Åström (CSC-IT, Espoo, Finland), Prof. Thomas Antretter, Prof. Christian Weiss, Jan Lubensky, and Gerold Wölfler (Montanuniversitaet Leoben) for their help and support.

Funding. Open access funding provided by Montanuniversität Leoben.

Open Access This article is distributed under the terms of the Creative Commons Attribution 4.0 International License (http://creativecommons. org/licenses/by/4.0/), which permits unrestricted use, distribution, and reproduction in any medium, provided you give appropriate credit to the original author(s) and the source, provide a link to the Creative Commons license, and indicate if changes were made.

\section{References}

1. Moser, P.: Less fines in aggregate and industrial minerals production - results of a European research project, in: Holmberg, R. (ed.): Proceedings of $3^{\text {rd }}$ EFEE World Conference on Explosives and Blasting, England: EFEE, 2005, pp 567-574

2. Ouchterlony, F.; Sifferlinger, N. A.; Brechelmacher, A.: Das eu ropäsiche Horizon 2020-Forschungsprojekt "Sustanable Low Impact Mining-SLIM", BHM Berg- und Hüttenmännische Monatshefte, 163 (2018), Nr. 2, pp 52-56

3. Sanchidrián, J. A.: SLIM: Technology for blasting to improve mining, in: Schunnesson, H.; Johansson, D. (eds.): Proceedings of $12^{\text {th }}$ International Symposium on Rock Fragmentation by Blasting, 2018, pp 783-793 
4. Steiner, H. J.: The significance of the Rittinger equation in presentday comminution technology, in: Proceedings of $17^{\text {th }}$ International Mineral Processing Congress, Bd I, 1991, pp 177-188

5. Thornton, D.; Kanchibotla, S. S.; Brunton, I.: Modelling the impact of rockmass and blast design variation on blast fragmentation, in: Marton, A. (ed.): Proceedings of Explo 2001 Conference, AusIMM: Carlton (u.a.), 2001, pp 197-205

6. Esen, S.; Onederra, I.; Bilgin, H. A.: Modelling the size of the crushed zone around a blasthole, Intenational Journal of Rock Mechanics and Mining Sciences 40(2003), pp 485-495

7. Onederra, I.; Esen, S.; Jankovic, A.: Estimation of fines generated by blasting-applications for the mining and quarrying industries, Mining Technology, Transactions of the Institute of Mining and Metallurgy A:113 (2004), pp A1-A11

8. Svahn, V.: Generation of fines in bench blasting, Lic. thesis, Gothenburg, Chalmers Univ. Technology, Dept. of Geology, Publication A104, 2003

9. Johansson, D.: Fragmentation and waste rock compaction in smallscale confined blasting, Lic. thesis 2008:30, Luleå: Luleå Univ. Technology, 2008

10. Åström, J. A.; Ouchterlony, F.; Linna, R. P.; Timonen, J.: Universal dynamic fragmentation in D dimensions, Physical review letters 92(2004), Nr. 24, pp 245506-1/4

11. Åström, J. A.: Statistical models of brittle fragmentation, Advances in Physics 55(2006), Nr. 3-4, pp 247-278

12. Ouchterlony, F; Moser, P.: On the branching-merging mechanism during dynamic crack growth as a major source of fines in rock blasting, in: Singh, P. K.; Sinha, A. (eds.): Rock Fragmentation by Blasting, Proceedings of $10^{\text {th }}$ International Symposium on Rock Fragmentation by Blasting, USA, Boca Raton (u.a.): CRC Press, 2012, pp 65-75

13. Kukolj, I.; Iravani, A.; Ouchterlony, F.; Weiss, C.; Lubensky, J.: Filming blast fragmentation of rock and mortar cylinders, in: Schunnesson, H.; Johansson, D. (eds.): Rock Fragmentation by Blasting, Pro- ceedings of $12^{\text {th }}$ International Symposium on Rock Fragmentation by Blasting, 2018, pp 483-494

14. Iravani, A.; Kukolj, I.; Ouchterlony, F.; Antretter, T.; Åström, J.: Modelling blast fragmentation of cylinders of mortar and rock, in: Schunnesson, H.; Johansson, D. (eds.): Rock Fragmentation by Blasting, Proceedings of $12^{\text {th }}$ International Symposium on Rock Fragmentation by Blasting, 2018, pp 597-610

15. Iravani, A.; Åström, J. A.; Ouchterlony, F.: Physical origin of the fine-particle problem in blasting fragmentation, Physical Review Applied, 10, 034001 (2018). https://doi.org/10.1103/PhysRevApplied. 10.034001

16. Schimek, P.: Improvement of fragmentation by blasting, Diss. Leoben, Montanuniv., Lehrst. f. Bergbaukunde, Bergtechnik und Bergwirtschaft, 2015

17. Sun, C.: Damage zone prediction for rock blasting, Doctoral Thesis, The University of Utah, Dept. of Mining Engineering, 2013

18. Åström, J. A.; Riikilä, T.I.; Tallinen, T.; Zwinger, T.; Benn, D.; Moore, J. C.; Timonen, J.: A particle based simulation model for glacier dynamics, The Cryosphere 7(2013), Nr. 5, pp 1591-1602

19. Åström, J. A.; Timonen, J.: Spontaneous formation of densely packed shear bands of rotating fragments, The European Physical Journal E 35 (2012), p 40

20. Kekäläinen, P.; Åström, J. A.; Timonen, J.: Solution for the fragmentation-size distribution in a crack branching model of fragmentation, Physical Review E 76, 026112 (2007)

21. Sanderson, D. J.; Nixon, C. W.: The use of topology in fracture network characterization, Journal of Structural Geology 72 (2015), pp 55-66

22. Ouchterlony, F.: Fragmentation characterization: the Swebrec function and its use in blast engineering, in: Sanchidrián, J. A. (ed.): Rock Fragmentation by Blasting, Proceedings of $9^{\text {th }}$ International Symposium on Rock Fragmentation by Blasting, Spain, Granada (u. a.): CRC Press, 2009, pp 3-22 